\title{
УДОСКОНАЛЕННЯ ТЕХНІКО-ТАКТИЧНОЇ ПІДГОТОВКИ КВАЛІФІКОВАНИХ СТРІЛЬЦІВ 3 ПНЕВМАТИЧНОЇ ГВИНТІВКИ НА ЕТАПІ СПЕЦІАЛІЗОВАНОї БАЗОВОЇ ПІДГОТОВКИ
}

\author{
Анатолій Лопатьєв ${ }^{1,2 A B C D}$, Андрій Демічковський ${ }^{1 \mathrm{ABCD}}$ \\ ${ }^{1}$ Львівський державний університет фізичної культури імені Івана Боберського \\ ${ }^{2}$ Центр математичного моделювання Інституту прикладних проблем \\ механіки і математики імені Я.С. Підстригача \\ Authors' Contribution: A - Study design; B - Data collection; C - Statistical analysis; D - Manuscript Preparation; E - Funds Collection
}

DOI: $10.17309 /$ jltm.2021.1.02

\begin{abstract}
Анотація
Мета дослідження - встановити особливості техніко-тактичної підготовки кваліфікованих стрільців 3 пневматичної гвинтівки на етапі спеціалізованої базової підготовки.

Матеріали та методи. Для вирішення поставлених завдань було використано наступні методи дослідження: аналіз та узагальнення науково-методичної літератури, педагогічні спостереження. Аналіз науковометодичної літератури дав змогу встановити, що кількість індивідуальних програм з підготовки стрільців з пневматичної гвинтівки не задовольняє сучасні потреби стрілецького спорту. Педагогічні спостереження використано для вивчення особливостей техніко-тактичного виконання змагальних вправ кваліфікованих спортсменів, а також їх рухових здібностей.

Результати. Аналіз змагальної діяльності дозволив визначити, що фази виконання пострілу «прицілювання», «виконання пострілу - активний постріл», «налаштування на постріл» $€$ інформативними показниками техніко-тактичних дій кваліфікованих спортсменів у стрільбі з пневматичної гвинтівки. Було проаналізовано ряд навчально-методичних документів: навчальна програма з підготовки стрільців з кульової стрільби для дитячо-юнацьких спортивних шкіл, спеціалізованих дитячо-юнацьких шкіл олімпійського резерву, шкіл вищої спортивної майстерності та навчальних закладів спортивного профілю; спеціалізована література 3 підготовки стрільців. У процесі аналізу визначено, що співвідношення наведених сторін підготовки не дає можливості проведення ефективного процесу підготовки спортсменів для досягнення високих спортивних результатів в межах діючих правил змагальної діяльності.

Висновки. Детальний аналіз спеціалізованої навчально-методичної літератури для стрільців з пневматичної гвинтівки дозволив встановити, що в групах спеціалізованої базової підготовки спортсменів усі види підготовки виглядають наступним чином: теоретична підготовка зменшується з 3,44 \% до 2,6 \%, загальна фізична зменшується з 15,0 \% до 13,2 \%, спеціальна фізична підготовка зменшується з 17,21 \% до 15 \%, технічна підготовка зростає 3 53,5 \% до 54,7 \%, участь у змаганнях збільшується з 9,05 \% до11,7 \%, інструкторська та суддівська практика зростає 3 1,8 \% до 2,8 \%.
\end{abstract}

Ключові слова: підготовка кваліфікованих спортсменів, техніко-тактичні дії, пневматична гвинтівка.

\section{Вступ}

Вдосконалення процесу підготовки стрільців з пневматичної гвинтівки вимагає правильного вибору навчально-методичних напрямів та виявлення резервів спортсменів. Доречно описати можливі шляхи вдосконалення системи спортивної підготовки в стрільбі кульовій наступним шляхом: орієнтація на індивідуальні

( ) Лопатьєв, А, Демічковський, А., 2021. здібності кожного спортсмена; побудова системи підготовки та визначення раціональної структури спортивної діяльності; розробка індивідуальних програм підготовки (Kurzawski 2005; Kijowski 2006; Власов, Лопатьєв, Виноградський, \& Демічковський 2010).

Фахівцями зі стрільби з пневматичної гвинтівки було запропоновано методику виділення ключових елементів та їх характеристика під час виконання стрілецької вправи для встановлення наявності або відсутності взаємозв’язку між елементами виконання вправи в ку- 
Lopatiev, A., \& Demichkovskyi, A. (2021). Improving the Technical and Tactical Training of Skilled Rifles with an Air Rifle at the Stage of Specialized Basic Training

льовій стрільбі (Власов, Демічковський, Іващенко, Лопатьєв, Пітин, П’янило, \& Худолій 2016; Демічковський 2019; Pyanylo, Sobko, Pyanylo, Petrus, \& Demichkovsky, 2020).

Удосконалення техніко-тактичної підготовки стрільців 3 пневматичної гвинтівки є одним 3 ключових елементів вимог великого спорту у підготовці спортсменів, що можливо лише шляхом поглибленої індивідуалізації. Враховуючи інтенсивну зміну правил змагальної діяльності, що призводить до збільшення навчально-тренувального та змагального навантаження на спортсмена було запропоновано виокремити тактичну підготовку окремим блоком у багаторічній системі підготовки кваліфікованих стрільців (Kijowski 2006; Лопатьєв, Пітин, \& Демічковський, 2017; Демічковський, 2017).

Наявна спеціалізована наукова та навчально-методична література не враховує сучасного характеру підготовки стрільців з пневматичної гвинтівки, відсутні методичні рекомендації до індивідуалізації навчальнотренувального процесу, а також індивідуальні програми 3 удосконалення підготовки спортсменів (Mon-López, \& Tejero-González, 2019; Mon-López, Bernardez-Vilaboa, Sillero-Quintana, \& Fernandez-Balbuena, 2021; Park, Kim, \& Kim, 2019).

Щодо питання підготовки спортсменів у складнокоординаційних видах спорту на етапі спеціалізованої базової підготовки наголошується, що повинні створюватися всебічні передумови до наступних етапів, метою яких є досягнення найвищих результатів (Платонов, 2004; Волков, Кукса, Дронов, Старінський, Богіно, Петросюк, 2009; Gladyszewski, Gladyszewska, 2012).

В даний час в підготовці кваліфікованих спортсменів у стрільбі з пневматичної гвинтівки не запропоновано конкретних методик або індивідуальних програм удосконалення техніко-тактичної підготовки стрільців. Головною метою індивідуальної програми є зосередження на специфічних особливостях виконання спортсменом техніко-тактичних елементів стрілецької вправи. Для того щоб розпочати написання такої програми потрібно проаналізувати спортивну діяльність спортсмена з виділенням ключових елементів та охарактеризувати їх.

Мета дослідження - встановити особливості техніко-тактичної підготовки кваліфікованих стрільців 3 пневматичної гвинтівки на етапі спеціалізованої базової підготовки.

\section{Матеріали та методи}

\section{Учасники дослідження}

У дослідженні взяли участь спортсмени зі стрільби 3 пневматичної гвинтівки під час змагальної діяльності чемпіонатів України, спортсмени (чоловічої та жіночої статі) зі спортивним званням МСУ (майстер спорту України, кількість спортсменів $\mathrm{n}=21$ ) і спортивним розрядом КМСУ (кандидат у майстри спорту України, кількість спортсменів $n=21)$. Припускається, що на основі аналізу фаз виконання пострілу під час стрільби з пневматичної гвинтівки можливо визначити особливості та інформативні показники змагальної діяльності стрільців різної спортивної майстерності.

\section{Організація дослідження}

Для вирішення поставлених завдань було використано наступні методи дослідження: аналіз та узагальнення науково-методичної літератури, педагогічні спостереження, обробка результатів. Аналіз науково-методичної літератури дав змогу встановити, що кількість індивідуальних програм не задовольняє сучасні потреби підготовки спортсменів. Педагогічне спостереження використано для вивчення особливостей техніко-тактичного виконання змагальних вправ кваліфікованих спортсменів, а також їх рухових здібностей. Проведення педагогічного спостереження відбувалося безпосередньо під час виконання змагальної діяльності на чемпіонатах України.

\section{Процедура тестування}

Здійснювалася відео-зйомка виконання стрільби 3 пневматичної гвинтівки кваліфікованими спортсменами. За допомогою методу хронометрування було визначено тривалість техніко-тактичних елементів виконання пострілу.

Обладнання: відеокамера, секундомір.

\section{Статистичний аналіз}

Для визначення нормальності розподілу результатів тестування використовувався критерій Шапіро-Уілка.

Вираховувались такі параметри: середня арифметична величина, стандартне відхилення. Оцінювання достовірності різниці статистичних показників проводилось за допомогою t-критерію Стьюдента.

\section{Результати}

Постріл як одиниця виконання навчально-тренувальної та змагальної діяльності розподілявся на фази («прицілювання», «виконання пострілу - активний постріл», «налаштування напостріл», «загальний час»). Такий поділ надає можливість ефективно проаналізувати рівень техніко-тактичної підготовленості стрільця з пневматичної гвинтівки, що у свою чергу надасть можливість покращити ефективність процесу підготовки стрільців на основі написаних індивідуальних програм вдосконалення техніко-тактичної підготовки на етапі спеціалізованої базової підготовки.

В спеціалізованій навчально-методичній літературі вказується, що зміст спортивної підготовки стрільців 3 пневматичної гвинтівки на етапі спеціалізованої базової підготовки є: розвиток загальних і спеціальних фізичних якостей; підвищення рівня техніко-тактичної майстерності, розвиток вольових і спеціальних психічних якостей; збільшення тренувальних і змагальних навантажень, доведення їх величин до вимог великого стрілецького спорту.

Розглядаючи техніко-тактичну підготовку можемо наголосити, що: технічна підготовка - це вдосконалення спортивної техніки шляхом зміни динамічних та кінематичних параметрів структури рухів під час виконання пострілу з урахуванням індивідуальних особливостей 
спортсмена, відповідність техніки виконання сучасним умовам змагальної діяльності та морфо-функціональним можливостям організму спортсмена під час виконання пострілу за змагальної вправи, забезпечення стійкості техніки до дії збурюючих чинників; тактична підготовка - вдосконалення та розробка тактики шляхом аналізу особливостей майбутніх змагань, з урахуванням їх умов, оволодіння головними елементами, прийомами, варіантами тактичних дій під час виконання пострілу у змаганнях.

Проаналізувавши науково-методичну документацію встановлено, що в навчальному плані багаторічної підготовки програми з підготовки стрільців зі стрільби кульової для дитячо-юнацьких спортивних шкіл, спеціалізованих дитячо-юнацьких шкіл олімпійського резерву, шкіл вищої спортивної майстерності та навчальних закладів спортивного профілю вказано: теоретична підготовка становить - 3,44\% - 2,6\%; загальна фізична підготовка - 15,0\% - 13,2\%; спеціальна фізична підготовка - 17,21\% - 15,0\%; технічна підготовка - 53,5\% $54,7 \%$; участь у змаганнях, складання нормативів - 9,05\% - 11,7\%; інструкторська та суддівська практика - 1,8\% - 2,8\% (табл.1).

У таблиці 2 і 3 наведені порівняння витрат часу на виконання пострілів у стрільбі з пневматичної гвинтівки стрільцями різної кваліфікації для спортсменів чоловічої та жіночої статі які свідчать, що за критерієм Шапіро-Уілка емпіричні дані відповідають нормальному розподілу на рівні значущості $\alpha(\mathrm{n})=0,05, \mathrm{a}(\mathrm{n})=0,01$, $\mathrm{a}$ витрати часу $є$ надзвичайно важливим показником підготовленості спортсмена в кульовій стрільбі з гвинтівки, як технічної так і тактичної.

Отримані результати дозволили встановити, що у чоловіків спортивної кваліфікації МСУ середні витрати часу на кожен техніко-тактичний елемент сягають наступних величин: «прицілювання» - 15,8 c, «виконання

Таблиця 1. Навчальний план багаторічної підготовки, годин (Волков, Кукса, Дронов, Старінський, Богіно, Петросюк, 2009)

\begin{tabular}{|c|c|c|c|c|c|c|c|c|c|c|}
\hline \multirow{4}{*}{ Вид підготовки } & \multicolumn{10}{|c|}{ Група } \\
\hline & \multicolumn{2}{|c|}{$\begin{array}{r}\text { Початкової } \\
\text { підготовки }\end{array}$} & \multicolumn{4}{|c|}{$\begin{array}{c}\text { Попередньої базової } \\
\text { підготовки }\end{array}$} & \multicolumn{3}{|c|}{$\begin{array}{c}\text { Спеціалізованої } \\
\text { базової підготовки }\end{array}$} & \multirow[t]{2}{*}{$\begin{array}{c}\text { Підготовки до вищих } \\
\text { досягнень }\end{array}$} \\
\hline & \multicolumn{9}{|c|}{\begin{tabular}{|l} 
Рік навчання \\
\end{tabular}} & \\
\hline & 1-й & 2-й & 1-й & 2-й & 3-й & 4-й & 1-й & 2-й & 3-й & Увесь термін \\
\hline Теоретична підготовка & 20 & 20 & 20 & 24 & 24 & 28 & 38 & 38 & 34 & 34 \\
\hline Загальна фізична підготовка & 80 & 90 & 110 & 130 & 154 & 162 & 166 & 168 & 170 & 174 \\
\hline $\begin{array}{l}\text { Спеціальна фізична підго- } \\
\text { товка }\end{array}$ & 36 & 48 & 92 & 120 & 140 & 160 & 190 & 192 & 194 & 196 \\
\hline Технічна підготовка & 136 & 202 & 310 & 334 & 444 & 482 & 590 & 652 & 704 & 852 \\
\hline $\begin{array}{l}\text { Участь у змаганнях, складан- } \\
\text { ня нормативів }\end{array}$ & 4 & 8 & 20 & 36 & 56 & 72 & 100 & 120 & 150 & 180 \\
\hline $\begin{array}{l}\text { Інструкторська та суддівська } \\
\text { практика }\end{array}$ & - & - & - & - & 10 & 16 & 20 & 24 & 36 & 36 \\
\hline Усього: & 276 & 368 & 552 & 644 & 828 & 920 & 1104 & 1194 & 1288 & 1472 \\
\hline
\end{tabular}

Таблиця 2. Розрахунок емпіричних даних за критерієм Шапіро-Уілка, чоловіки

\begin{tabular}{|c|c|c|c|c|c|c|c|c|c|c|}
\hline \multicolumn{6}{|c|}{ MCУ } & \multicolumn{5}{|c|}{ КМСУ } \\
\hline № п/ п & $\mathbf{x}$ & $\bar{k}$ & delta & alpha & $d \times a$ & $\mathbf{x}$ & $\mathbf{k}$ & delta & alpha & $d \times a$ \\
\hline 1 & 540,3 & 1 & 80,5 & 0,5739 & 46,19895 & 484,8 & 1 & 131,1 & 0,5739 & 75,23829 \\
\hline 2 & 578,0 & 2 & 34,8 & 0,3291 & 11,45268 & 558,0 & 2 & 43,6 & 0,3291 & 14,34876 \\
\hline 3 & 579,0 & 3 & 33,3 & 0,2141 & 7,12953 & 559,0 & 3 & 36,4 & 0,2141 & 7,79324 \\
\hline 4 & 596,0 & 4 & 9,2 & 0,1224 & 1,12608 & 567,4 & 4 & 26,7 & 0,1224 & 3,26808 \\
\hline 5 & 596,4 & 5 & 2,3 & 0,0399 & 0,09177 & 571 & 5 & 3 & 0,0399 & 0,1197 \\
\hline 6 & 598,7 & & & & & 574 & & & & \\
\hline 7 & 605,2 & & & $\mathrm{~b}=$ & 66,00 & 594,1 & & & & 100,7681 \\
\hline 8 & 612,3 & & & $\mathrm{~W}=$ & 0,883808 & 595,4 & & & & 0,858039 \\
\hline 9 & 612,8 & & & $\mathrm{~W}(0,05 ; \mathrm{n})=$ & 0,842 & 601,6 & & & $\mathrm{~W}(0,05 ; 1$ & 0,842 \\
\hline 10 & 620,8 & & & $\mathrm{~W}(0,01 ; \mathrm{n})=$ & 0,781 & 615,9 & & & $\mathrm{~W}(0,01 ; \mathrm{r}$ & 0,781 \\
\hline $\begin{array}{l}\text { Стандартне } \\
\text { відхилення }\end{array}$ & 23,4 & & & & & 36,3 & & & & \\
\hline
\end{tabular}


Lopatiev, A., \& Demichkovskyi, A. (2021). Improving the Technical and Tactical Training of Skilled Rifles with an Air Rifle at the Stage of Specialized Basic Training

Таблиця 3. Розрахунок емпіричних даних за критерієм Шапіро-Уілка, жінки

\begin{tabular}{|c|c|c|c|c|c|c|c|c|c|c|}
\hline \multicolumn{6}{|c|}{ МСУ } & \multicolumn{5}{|c|}{ КМСУ } \\
\hline № п/ா/ா & $\mathrm{x}, \mathrm{s}$ & $\mathbf{k}$ & delta & alpha & $d \times a$ & $\mathrm{x}, \mathrm{s}$ & $\mathbf{k}$ & delta & alpha & $d \times a$ \\
\hline 1 & 590,0 & 1 & 19,6 & 0,5601 & 10,97796 & 564,0 & 1 & 41 & 0,5601 & 22,9641 \\
\hline 2 & 590,1 & 2 & 18,6 & 0,3315 & 6,1659 & 569,0 & 2 & 27,7 & 0,3315 & 9,18255 \\
\hline 3 & 597,4 & 3 & 10,1 & 0,2260 & 2,2826 & 577,0 & 3 & 17,4 & 0,2260 & 3,9324 \\
\hline 4 & 601,5 & 4 & 5,8 & 0,1429 & 0,82882 & 579,0 & 4 & 15,3 & 0,1429 & 2,18637 \\
\hline 5 & 603,4 & 5 & 1,9 & 0,0695 & 0,13205 & 589,0 & 5 & 4 & 0,0695 & 0,278 \\
\hline 6 & 604,0 & & & & & 590,1 & & & & \\
\hline 7 & 605,3 & & & & & 593,0 & & & & \\
\hline 8 & 607,3 & & & $\mathrm{~b}=$ & 20,3873 & 594,3 & & & $\mathrm{~b}=$ & 38,54342 \\
\hline 9 & 607,5 & & & $\mathrm{~W}=$ & 0,86449 & 594,4 & & & $\mathrm{~W}=$ & 0,94279 \\
\hline 10 & 608,7 & & $\mathrm{~W}(0,05 ;$ & $1)=$ & 0,850 & 596,7 & & $\mathrm{~W}(0,05$ & n) $=$ & 0,850 \\
\hline 11 & 609,6 & & $\mathrm{~W}(0,01 ; 1$ & 1)= & 0,781 & 605,0 & & $\mathrm{~W}(0,01 ;$ & n) $=$ & 0,781 \\
\hline $\begin{array}{l}\text { Стандартне } \\
\text { відхилення }\end{array}$ & 7,3 & & & & & 13,2 & & & & \\
\hline
\end{tabular}

Таблиця 4. Середні значення витрат часу на виконання стрільби з пневматичної гвинтівки, чоловіки

\begin{tabular}{|c|c|c|c|c|c|c|}
\hline \multirow{2}{*}{$\begin{array}{c}\text { Спортивна май- } \\
\text { стерність }\end{array}$} & \multirow[t]{2}{*}{ Постріли } & \multicolumn{3}{|c|}{ Елементи пострілу } & \multirow{2}{*}{$\begin{array}{c}\text { Загальний час } \\
\text { (c) }\end{array}$} & \multirow{2}{*}{$\begin{array}{c}\text { Результат } \\
\text { (очки) }\end{array}$} \\
\hline & & $\begin{array}{r}\text { Налаштуванг } \\
\text { постріл (c }\end{array}$ & лювюа & $\begin{array}{c}\text { c) “Виконання по- } \\
\text { стрілу - активний } \\
\text { постріл” (c) }\end{array}$ & & \\
\hline \multirow[t]{6}{*}{$\overline{\mathrm{MCY}}$} & $1-10$ & 26,6 & 15,6 & 16,3 & 58,6 & 9,8 \\
\hline & $11-20$ & 28,8 & 16,4 & 16,4 & 61,6 & 10,0 \\
\hline & $21-30$ & 29,7 & 16,1 & 16,7 & 62,4 & 9,8 \\
\hline & $31-40$ & 28,2 & 16,3 & 15,2 & 59,4 & 9,9 \\
\hline & $41-50$ & 27,1 & 15,0 & 16,0 & 58,2 & 9,9 \\
\hline & $51-60$ & 27,4 & 15,7 & 16,1 & 59,2 & 9,9 \\
\hline \multicolumn{2}{|l|}{ Середні значення } & 28,0 & 15,8 & 16,1 & 59,9 & 9,9 \\
\hline \multirow[t]{6}{*}{$\overline{\mathrm{KMCY}}$} & $1-10$ & 28,3 & 18,0 & 15,2 & 63,0 & 9,5 \\
\hline & $11-20$ & 30,8 & 19,2 & 17,8 & 69,2 & 9,5 \\
\hline & $21-30$ & 33,4 & 19,5 & 17,5 & 71,0 & 9,6 \\
\hline & $31-40$ & 31,9 & 19,4 & 17,5 & 69,8 & 9,5 \\
\hline & $41-50$ & 29,7 & 17,1 & 15,0 & 62,5 & 9,6 \\
\hline & $51-60$ & 29,1 & 17,0 & 15,5 & 61,8 & 9,5 \\
\hline Середні значення & & 30,5 & 18,4 & 16,4 & 66,2 & 9,5 \\
\hline
\end{tabular}

пострілу - активний постріл» - 16,1 с, «налаштування на постріл» - 28,0 (табл. 4). У чоловіків зі спортивною кваліфікацією КМСУ: «прицілювання» - 15,4 с, «виконання пострілу - активний постріл» - 16,4 c, «налаштування на постріл» - 30,5 с.

Відповідно у таблиці 5 вказано, що у жінок зі спортивною кваліфікацією МСУ середні величини витрат часу на елементи виконання пострілу є наступними: «прицілювання» - 18,1 с, «виконання пострілу - активний постріл» - 18,7 с, «налаштування на постріл» - 25,0. У жінок зі спортивною кваліфікацією КМСУ показники сягають наступних величин: «прицілювання» - 16,2 с, «виконання пострілу - активний постріл» - 14,3 с, «налаштування на постріл» - 23,7.

\section{Дискусія}

Припускалося, що на основі аналізу навчально-методичної документації підготовки стрільців із пневматичної гвинтівки на етапі спеціалізованої базової підготовки можливо визначити особливості використання спеціально-підготовчих засобів для удосконалення тех- 
ISSN 2708-7581 (Online). ISSN-L 2708-7573. Journal of Learning Theory and Methodology. 2021. Volume 2, Number 1

Таблиця 5. Середні значення витрат часу на виконання стрільби з пневматичної гвинтівки, жінки

\begin{tabular}{|c|c|c|c|c|c|c|}
\hline \multirow{3}{*}{$\begin{array}{c}\text { Спортивна } \\
\text { майстерність }\end{array}$} & \multirow{3}{*}{ Постріли } & \multicolumn{5}{|c|}{ Середні значення } \\
\hline & & \multicolumn{3}{|c|}{ Елементи пострілу } & \multirow[b]{2}{*}{$\begin{array}{l}\text { Загальний час } \\
\text { (c) }\end{array}$} & \multirow[b]{2}{*}{ Результат (очки) } \\
\hline & & $\begin{array}{c}\text { Налаштування на } \\
\text { постріл (c) }\end{array}$ & Прицілювання (c) & $\begin{array}{c}\text { “Виконання по- } \\
\text { стрілу - активний } \\
\text { постріл” (c) }\end{array}$ & & \\
\hline \multirow[t]{6}{*}{ MCY } & $1-10$ & 22,0 & 18,7 & 17,6 & 58,3 & 10,0 \\
\hline & $11-20$ & 25,5 & 21,3 & 19,4 & 66,0 & 10,1 \\
\hline & $21-30$ & 26,5 & 21,2 & 17,5 & 65,2 & 10,0 \\
\hline & $31-40$ & 25,0 & 21,0 & 19,5 & 65,6 & 10,1 \\
\hline & $41-50$ & 25,3 & 18,5 & 19,3 & 63,2 & 10,0 \\
\hline & $51-60$ & 25,6 & 18,1 & 19,1 & 62,6 & 10,1 \\
\hline Середні значення & & 25,0 & 19,8 & 18,7 & 63,5 & 10,1 \\
\hline \multirow[t]{6}{*}{ КМСУ } & $1-10$ & 21,2 & 16,5 & 14,4 & 52,1 & 9,7 \\
\hline & $11-20$ & 23,5 & 16,8 & 15,3 & 55,5 & 9,7 \\
\hline & $21-30$ & 25,2 & 17,0 & 14,5 & 56,7 & 9,8 \\
\hline & $31-40$ & 24,8 & 16,0 & 13,8 & 54,6 & 9,6 \\
\hline & $41-50$ & 23,5 & 15,5 & 13,9 & 52,9 & 9,9 \\
\hline & $51-60$ & 23,9 & 15,4 & 14,1 & 53,5 & 9,7 \\
\hline Середні значення & & 23,7 & 16,2 & 14,3 & 54,2 & 9,7 \\
\hline
\end{tabular}

ніко-тактичної підготовки. Аналіз науково-методичної літератури показав, що наявна не відповідність між обсягом навчально-тренувального навантаження стрільців на етапі спеціалізованої підготовки та ефективністю підготовки (Pavlyuk, Pityn, Pavlyuk, Chopyk,Antoniuk, \& Soltyk, 2020; Petrovič, Benčuriková, Červenka, \& Putala, 2020; Spancken, Steingrebe, \& Stein, 2021).

Виявлено, що у спортсменів різної спортивної майстерності МСУ і КМСУ, як чоловічої та жіночої статі критерій Шапіро-Уілка свідчить про відповідність емпіричних даних нормальному розподілу на рівні значущості $\alpha(\mathrm{n})=0,05, \alpha(\mathrm{n})=0,01$, що дає змогу продовжувати подальший детальний аналіз елементів стрільців 3 пневматичної гвинтівки для написання методики або індивідуальної програми удосконалення техніко-тактичної підготовки на етапі спеціалізовано базової підготовки.

У результаті аналізу встановлено, що тактична підготовка не відокремлена як окремий напрямок за яким відбувається професійна підготовка стрільців на етапі спеціалізованої базової підготовки. Наведені пропозиції доповнюють засоби та методи техніко-тактичної підготовки як окремих напрямів підготовки, що доповнюють один одного.

На нашу думку тактична підготовка як елемент спортивної підготовки стрільців з пневматичної гвинтівки має бути відображена у програмі окремим напрямом. Шляхи реалізації тактичної підготовки: за допомогою імітаційних тренувань, відпрацювати в навчально-тренувальних умовах вплив збурюючих чинників. В навчальній програмі з підготовки стрільців зі стрільби кульової для дитячо-юнацьких спортивних шкіл, спеціалізованих дитячо-юнацьких шкіл олімпійського резерву, шкіл вищої спортивної майстерності та навчальних закладів спортивного профілю зазначено, що метою на етапі спеціалізова- ної базової підготовки $є$ подальше розвинення загальних та спеціальних фізичних якостей, підвищення рівня техніко-тактичної майстерності в обраному виді зброї.

Практика свідчить, що спеціально-підготовчі вправи на етапі спеціальної базової підготовки позитивно впливають на якість підготовки кваліфікованих спортсменів, тому що вони включають елементи змагальної діяльності та дії, які за формою та структурою наближені до них. Спеціально-підготовчі вправи допоможуть спортсменові підвищити функціональний потенціал організму, адаптувавши його до специфічних умов змагальної діяльності.

Засобами спеціально-підготовчих вправ виступають фізичні вправи які спрямовані на удосконалення складно координаційних якостей стрільця, а саме: оцінці і регуляції динамічних та просторо-часових параметрів рухів, збереження стійкості, орієнтація в просторі, довільне розслаблення м'язів та координованість рухів (рис.1). В кожного окремого спортсмена (а також статі) вказані здібності виявляються не в чистому вигляді, а в спільній взаємодії. В стрільбі кульовій окремі координаційні здібності є провідними, а інші допоміжними, залежно від зовнішніх умов можлива миттєва зміна різних координаційних здібностей (Пітин, 2015).

Науковці та практики зі спортивної підготовки рекомендують використовувати вправи біля граничної (90\% максимального рівня) та граничної складності (більше 95\% максимального рівня), однак об’єм неповинен перевищувати - 10-15\% загального об’єму в навчально-тренувальному навантажені (Ihalainen, Mononen, Linnamo, \& Kuitunen, 2018; Ladommatos, 2019; Krivtsov, \& Nechushkin, 2020). Для повноцінного сприяння розвитку спеціальних якостей у кваліфікованих спортсменів на нашу думку доцільно розпочинати з вправ помірної (60- 


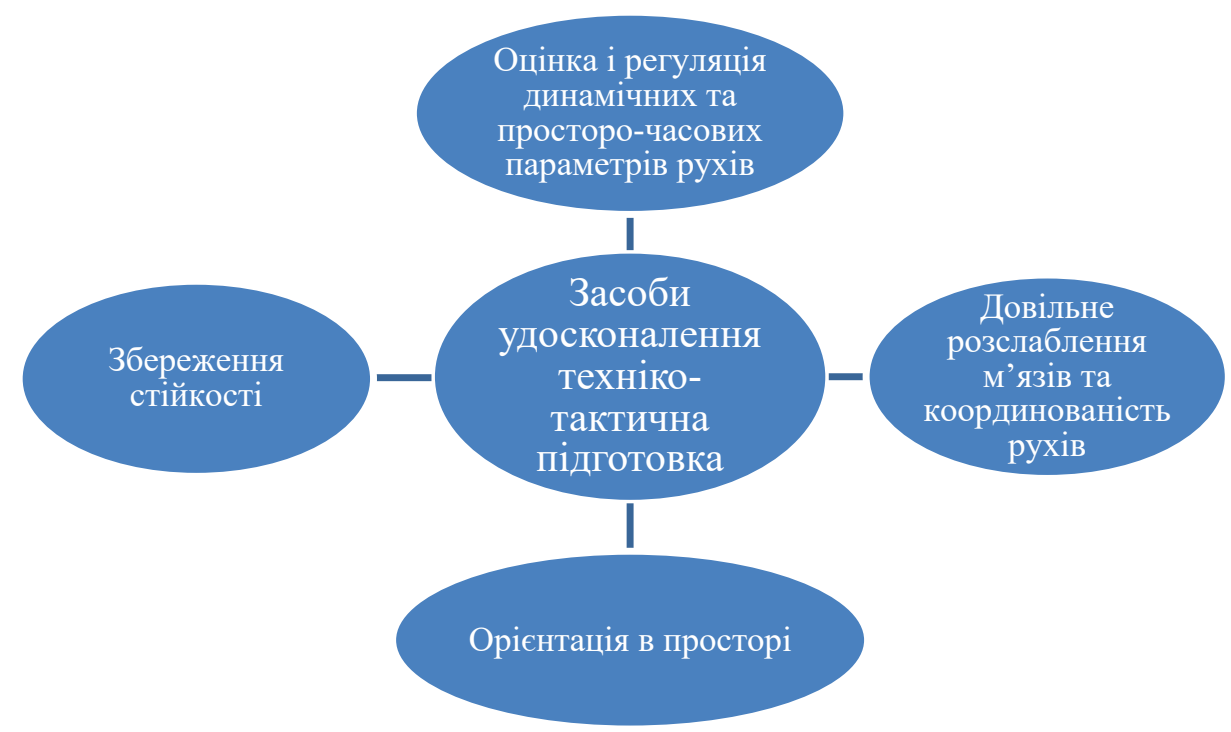

Рис. 1. Засоби удосконалення техніко-тактичної підготовки

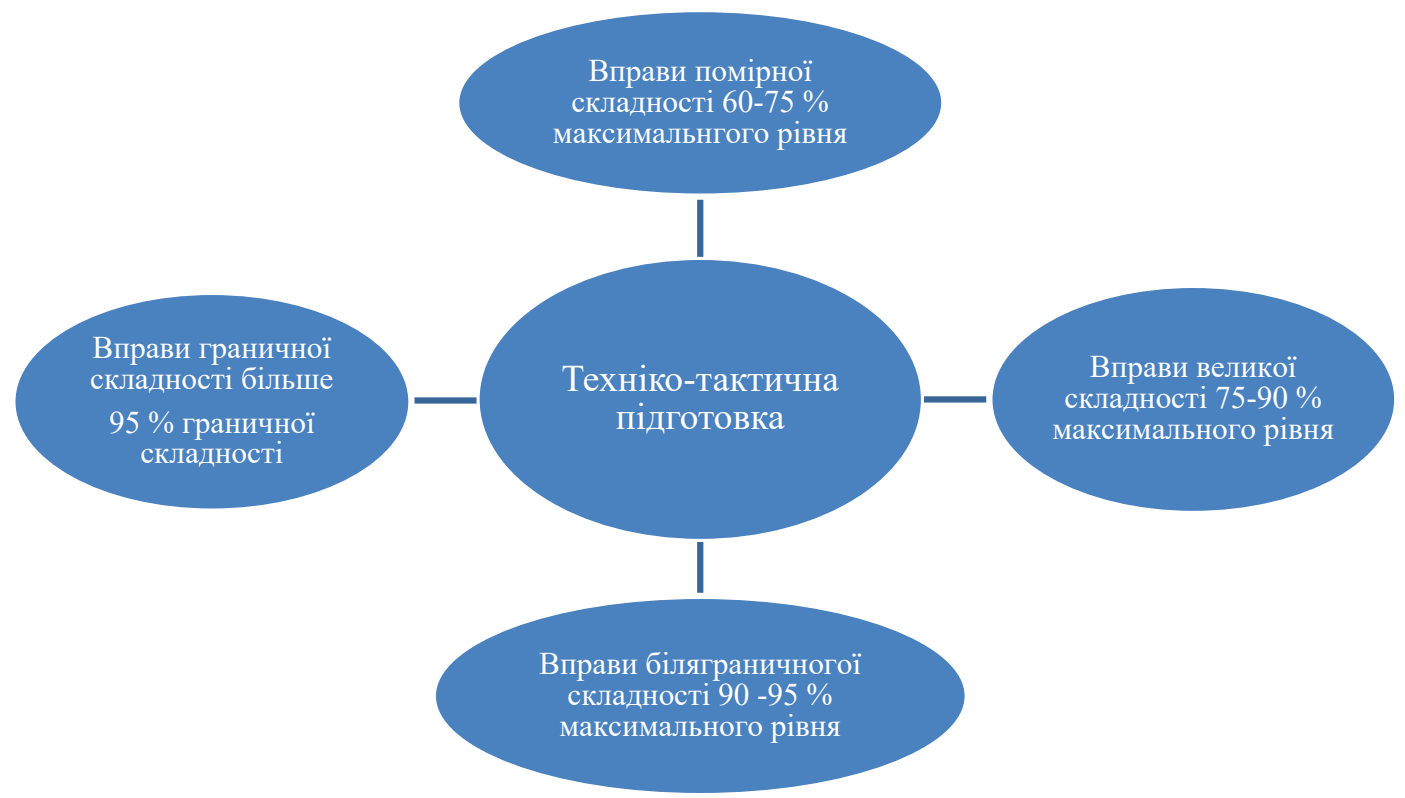

Рис. 2. Складові елементи удосконалення техніко-тактичної підготовки

75\% максимального рівня) та великої складності (75-90\% максимального рівня), поступово переходячи до вправ біля граничної (90\% максимального рівня) та граничної складності (більше 95\% максимального рівня) (рис.2). За тривалістю вправи помірної складності займатимуть 30-40\% а великої складності 40-50\% загального об’єму в навчально-тренувальному навантажені.

\section{Висновки}

В роботі встановлено особливості техніко-тактичного удосконалення стрільців 3 пневматичної гвинтівки на етапі спеціалізованої базової підготовки. Наголошено, що використання спеціально-підготовчих вправ з роз- витку координаційних якостей позитивно впливають на техніко-тактичну підготовленість спортсменів шляхом підвищення функціонального потенціалу організму.

Детальний аналіз спеціалізованої навчально-методичної літератури для стрільців з пневматичної гвинтівки дозволив встановити, що в групах спеціалізованої базової підготовки спортсменів усі види підготовки виглядають наступним чином: теоретична підготовка зменшується з 3,44\% до 2,6\%, загальна фізична зменшується 3 15,0\% до 13,2\%, спеціальна фізична підготовка зростає з 17,21\% до 15\%, технічна підготовка зростає 3 $53,5 \%$ до 54,7\%, участь у змаганнях збільшується з 9,05\% до $11,7 \%$, інструкторська та суддівська практика зростає з $1,8 \%$ до $2,8 \%$. 


\section{Література}

Kurzawski, K. (2005). Metody nauczania i kontroli taktyki strzelania. Strzelectwo sportowe (Nowoczesne rozwiązania szkoleniowe), zeszyt nr 2, Wrocław.

Kijowski, A. (2006). Wybrane elementy przygotowania taktycznego. Środki treningowe z zakresu przygotowania taktycznego stosowane w treningu strzeleckim. Strzelectwo sportowe (Nowoczesne rozwiązania szkoleniowe), zeszyt $n r$ 3, Wrocław.

Власов, А.П., Лопатьєв, А.О., Виноградський, Б.А., \& Демічковський А.П. (2010). Аналіз рухових дій привиконанні стрілецьких вправ. Актуальні проблеми сучасної біомеханіки фізичного виховання та спорту. Серія: Педагогічні науки. Фізичне виховання та спорт. Вісник, (81). ЧДПУ ім. Т.Г. Шевченка. Чернігів, 561-565.

Власов, А., Демічковський, А., Іващенко, О., Лопатьєв, А., Пітин, М., П’янило, Я., \& Худолій, О. (2016). Системний підхід і математичне моделювання біологічних та природних об'єктів і процесів. Фізико-математичне моделювання та інформаційні технологіi, (23), 17-28.

Демічковський, А. П. (2019). Показники технікотактичних дій кваліфікованих спортсменів у стрільбі з пневматичної гвинтівки. Теорія та методика бізичного виховання, 19(4), 186-192. https://doi.org/10.17309/tmfv.2019.4.04

Pyanylo, Y., Sobko, V., Pyanylo, H., Petrus, M., \& Demichkovsky, A. (2020). Processing of Digital Information on the Basis of Orthogonal and Biorthogonal Polynomials. IEEE 6th International Conference on Methods and Systems of Navigation and Motion Control (MSNMC), 114-117.

Лопатьєв, А., Пітин, М., \& Демічковський, А. (2017). Основні визначення і положення системного підходу, математичного моделювання та інформаційних технологій спортивної науки. Теорія та методика фізичного виховання, 17(3), 117-125. https://doi.org/10.17309/tmfv.2017.3.1196

Демічковський, А. (2017). Проблема тактичної підготовки в багаторічній підготовці спортсменів із кульової стрільби. Спортивний вісник Придніпров'я, (2), 54-58.

Mon-López, D., Bernardez-Vilaboa, R., Sillero-Quintana, M., \& Fernandez-Balbuena, A. A. (2021). Air shooting competition effects on visual skills depending on the sport level. European Journal of Sport Science. https://doi.org/10.1080/17461391.2021.1874540

Mon-López, D., \& Tejero-González, C. M. (2019). Validity and reliability of the TargetScan ISSF Pistol \& Rifle application for measuring shooting performance. Scandinavian Journal of Medicine and Science in Sports, 29(11), 1707-1712. https://doi.org/10.1111/sms.13515

Park, H.-K., Kim, D.-W., \& Kim, T.-H. (2019). Improvements of Shooting Performance in Adolescent Air Rifle Athletes After 6-Week Balance and Respiration Training Programs. Journal of sport rehabilitation, 28(6), 552-557.

Платонов, В.Н. (2004). Система подготовки спортсменов в олимпийском спорте. Общая теория и ее практические приложения. К.: Олимпийская література, 808.

Волков, О.І., Кукса, А.П., Дронов, В.А., Старінський, С.І., Богіно, В.I., \& Петросюк, А.М. (2009). Навчальна

\section{References}

Kurzawski, K. (2005). Metody nauczania i kontroli taktyki strzelania. Strzelectwo sportowe (Nowoczesne rozwiązania szkoleniowe), zeszyt $n r$ 2, Wrocław.

Kijowski, A. (2006). Wybrane elementy przygotowania taktycznego. Środki treningowe z zakresu przygotowania taktycznego stosowane w treningu strzeleckim. Strzelectwo sportowe (Nowoczesne rozwiązania szkoleniowe), zeszyt $n r$ 3, Wrocław.

Vlasov, A.P., Lopatiev, A.O., Vynohradskyi, B.A., \& Demichkovskyi A.P. (2010). Analiz rukhovykh dii pryvykonanni striletskykh vprav. Aktualni problemy suchasnoi biomekhaniky fizychnoho vykhovannia ta sportu. Seriia: Pedahohichni nauky. Fizychne vykhovannia ta sport. Visnyk, (81). ChDPU im. T.H. Shevchenka. Chernihiv, 561-565.

Vlasov, A., Demichkovskyi, A., Ivashchenko, O., Lopatiev, A., Pityn, M., Pianylo, Ya., \& Khudolii, O. (2016). Systemnyi pidkhid i matematychne modeliuvannia biolohichnykh ta pryrodnykh obiektiv i protsesiv. Fizyko-matematychne modeliuvannia ta informatsiini tekhnolohii, (23), 17-28.

Demichkovskyi, A. (2019). Indicators of Technical and Tactical Actions of Qualified Air Rifle Shooters. Teoriâ ta Metodika Fizičnogo Vihovannâ, 19(4), 186-192. https://doi.org/10.17309/tmfv.2019.4.04

Pyanylo, Y., Sobko, V., Pyanylo, H., Petrus, M., \& Demichkovsky, A. (2020). Processing of Digital Information on the Basis of Orthogonal and Biorthogonal Polynomials. IEEE 6th International Conference on Methods and Systems of Navigation and Motion Control (MSNMC), 114-117.

Lopatiev, A., Pityn, M., \& Demichkovskyi, A. (2017). Basic Definitions and Concepts of Systems Approach, Mathematical Modeling and Information Technologies in Sports Science. Teoriâ ta Metodika Fizičnogo Vihovannâ, 17(3), 117-125. https://doi.org/10.17309/tmfv.2017.3.1196

Demichkovskyi, A. (2017). Problema taktychnoi pidhotovky v bahatorichnii pidhotovtsi sportsmeniv iz kulovoi strilby. Sportyvnyi visnyk Prydniprovia, (2), 54-58.

Mon-López, D., Bernardez-Vilaboa, R., Sillero-Quintana, M., \& Fernandez-Balbuena, A. A. (2021). Air shooting competition effects on visual skills depending on the sport level. European Journal of Sport Science. https://doi.org/10.1080/17461391.2021.1874540

Mon-López, D., \& Tejero-González, C. M. (2019). Validity and reliability of the TargetScan ISSF Pistol \& Rifle application for measuring shooting performance. Scandinavian Journal of Medicine and Science in Sports, 29(11), 1707-1712. https://doi.org/10.1111/sms.13515

Park, H.-K., Kim, D.-W., \& Kim, T.-H. (2019). Improvements of Shooting Performance in Adolescent Air Rifle Athletes After 6-Week Balance and Respiration Training Programs. Journal of sport rehabilitation, 28(6), 552-557. Scopus.

Platonov, V.N. (2004). Sistema podgotovki sportsmenov $v$ olimpiiskom sporte. Obshchaia teoriia i ee prakticheskie prilozheniia. K.: Olimpiiskaia literatura, 808.

Volkov, O.I., Kuksa, A.P., Dronov, V.A., Starinskyi, S.I., Bohino, V.I., \& Petrosiuk, A.M. (2009). Navchalna prohrama dlia dytiacho-yunatskykh shkil olimpiiskoho rezervu, shkil vyshchoi sportyvnoi maisternosti ta navchalnykh zakladiv sportyvnoho profiliu. Kyiv: 63. 
Lopatiev, A., \& Demichkovskyi, A. (2021). Improving the Technical and Tactical Training of Skilled Rifles with an Air Rifle at the Stage of Specialized Basic Training

програма для дитячо-юнацьких шкіл олімпійського резерву, шкіл вищої спортивної майстерності та навчальних закладів спортивного профілю. Київ: 63.

Gładyszewski, G., \& Gładyszewska, B. (2012). Nowoczesne rozwiązania techniczne w sporcie strzeleckim. Strzelectwo sportowe (Nowoczesne rozwązania szkoleniowe), zeszyt $n r$ 9, Wrocław.

Pavlyuk, Y., Pityn, M., Pavlyuk, O., Chopyk, T., Antoniuk, O., \& Soltyk, O. (2020). Objectification of technical and tactical training of athletes in running target shooting. Journal of Physical Education and Sport, 20(2), 736-743. https://doi.org/10.7752/jpes.2020.02106

Petrovič, P., Benčuriková, L., Červenka, D., \& Putala, M. (2020). Impact of selected factors on performance in sporting shooting from air rifle in standing position. Journal of Physical Education and Sport, 20(2), 768-773. https://doi.org/10.7752/jpes.2020.02110

Spancken, S., Steingrebe, H., \& Stein, T. (2021). Factors that influence performance in Olympic air-rifle and small-bore shooting: A systematic review. PLoS ONE, 16(3). https://doi.org/10.1371/journal.pone.0247353

Пітин, М. (2015). Теоретична підготовка в спорті : монографія. Львів : ЛДУФК, 372.

Ihalainen, S., Mononen, K., Linnamo, V., \& Kuitunen, S. (2018). Which technical factors explain competition performance in air rifle shooting? International Journal of Sports Science and Coaching, 13(1), 78-85.

https://doi.org/10.1177/1747954117707481

Krivtsov, A. S., \& Nechushkin, Y. V. (2020). Hearing-impaired academic rifle shooting sport: Self-suggestion with ideomotor training model for competitive progress. Teoriya i Praktika Fizicheskoy Kultury, 2020(12), 70-72.

Ladommatos, N. (2019). Influence of air rifle pellet geometryon aerodynamic drag. Proceedings of the Institution of Mechanical Engineers, Part P: Journal of Sports Engineering and Technology.

https://doi.org/10.1177/1754337119831107
Gładyszewski, G., \& Gładyszewska, B. (2012). Nowoczesne rozwiązania techniczne w sporcie strzeleckim. Strzelectwo sportowe (Nowoczesne rozwąania szkoleniowe), zeszyt $n r$ 9, Wrocław.

Pavlyuk, Y., Pityn, M., Pavlyuk, O., Chopyk, T., Antoniuk, O., \& Soltyk, O. (2020). Objectification of technical and tactical training of athletes in running target shooting. Journal of Physical Education and Sport, 20(2), 736-743. https://doi.org/10.7752/jpes.2020.02106

Petrovič, P., Benčuriková, L., Červenka, D., \& Putala, M. (2020). Impact of selected factors on performance in sporting shooting from air rifle in standing position. Journal of Physical Education and Sport, 20(2), 768-773. https://doi.org/10.7752/jpes.2020.02110

Spancken, S., Steingrebe, H., \& Stein, T. (2021). Factors that influence performance in Olympic air-rifle and small-bore shooting: A systematic review. PLoS ONE, 16(3). https://doi.org/10.1371/journal.pone.0247353

Pityn, M. (2015). Teoretychna pidhotovka v sporti : monohrafiia. Lviv : LDUFK, 372.

Ihalainen, S., Mononen, K., Linnamo, V., \& Kuitunen, S. (2018). Which technical factors explain competition performance in air rifle shooting? International Journal of Sports Science and Coaching, 13(1), 78-85.

https://doi.org/10.1177/1747954117707481

Krivtsov, A. S., \& Nechushkin, Y. V. (2020). Hearing-impaired academic rifle shooting sport: Self-suggestion with ideomotor training model for competitive progress. Teoriya i Praktika Fizicheskoy Kultury, 2020(12), 70-72. Scopus.

Ladommatos, N. (2019). Influence of air rifle pellet geometryon aerodynamic drag. Proceedings of the Institution of Mechanical Engineers, Part P: Journal of Sports Engineering and Technology. https://doi.org/10.1177/1754337119831107

\title{
IMPROVEMENT OF TECHNICAL AND TACTICAL TRAINING OF QUALIFIED AIR RIFLE SHOOTERS AT THE STAGE OF SPECIALIZED BASIC TRAINING
}

\author{
Anatolii Lopatiev ${ }^{1,2 A B C D}$, Andrii Demichkovskyi ${ }^{1 \mathrm{ABCD}}$ \\ ${ }^{1}$ Ivan Bobersky Lviv State University of Physical Culture \\ ${ }^{2}$ Center for Mathematical Modeling of Ya. S. Pidstryhach Institute for Applied Problems \\ of Mechanics and Mathematics of the National Academy of Sciences of Ukraine
}

Authors' Contribution: A - Study design; B - Data collection; C - Statistical analysis; D - Manuscript Preparation; E - Funds Collection

Report. Article: 8 p., 5 tabl., 2 fig., 21 sources.

The purpose of the study was to identify the peculiarities of technical and tactical training of qualified air rifle shooters at the stage of specialized basic training.

Materials and methods. The following research methods were used to solve the tasks set: analysis and generalization of scientific and methodological literature, pedagogical observations. The analysis of scientific and methodological literature showed that the number of individual programs for training air rifle shooters does not meet today's needs of shooting sport.
Pedagogical observations were used to study the peculiarities of technical and tactical performance of competitive exercises of qualified athletes, as well as their motor abilities.

Results. The analysis of competitive activity showed that the stages of shooting "aiming", "performing a shot - active shot", "getting ready for a shot" are informative indicators of technical and tactical actions of qualified air rifle shooting athletes. A number of educational and methodological documents were analyzed: a program for training rifle and pistol shooters for chil- 
dren and youth sports schools, specialized children and youth schools of the Olympic reserve, schools of high sports mastery and sports educational institutions; specialized literature on training shooters. The analysis revealed that the ratio of the above aspects of training does not allow for effective preparation of athletes to achieve high sports results within the current rules of competitive activity.

Conclusions. A detailed analysis of specialized educational and methodological literature for air rifle shooters showed that in the groups of specialized basic training of athletes all types of training are as follows: theoretical training decreases from $3.44 \%$ to $2.6 \%$, general physical training decreases from 15.0 $\%$ to $13.2 \%$, special physical training decreases from $17.21 \%$ to $15 \%$, technical training increases from $53.5 \%$ to $54.7 \%$, participation in competitions increases from $9.05 \%$ to $11.7 \%$, instructional and referee practice increases from $1.8 \%$ to $2.8 \%$.

Keywords: training of qualified athletes, technical and tactical actions, air rifle.

\section{Information about the authors:}

Lopatiev Anatolii: lopatiiv@gmail.com; https://orcid.org/0000-0002-4474-7558; Department of Shooting and Technical Sports, Lviv State University of Physical Culture, Centre of Mathematical Modelling of IAPMM named after Ya.S.Pidstryhach of NASU, Kostiushka St, 11, Lviv, 79007, Ukraine.

Demichkovskyi Andrii: snauper777@gmail.com; https://orcid.org/0000-0002-2049-9844; Department of Shooting and Technical Sports, Lviv State University of Physical Culture, Kostiushka St, 11, Lviv, 79007, Ukraine.

Cite this article as: Lopatiev, A., \& Demichkovskyi, A. (2021). Improving the Technical and Tactical Training of Skilled Rifles with an Air Rifle at the Stage of Specialized Basic Training. Journal of Learning Theory and Methodology, 2(1), 12-20. https://doi.org/10.17309/jltm.2021.1.02

Received: 15.01.2021. Accepted: 05.02.2021. Published: 28.02.2021

This work is licensed under a Creative Commons Attribution 4.0 International License (http://creativecommons.org/licenses/by/4.0). 